\title{
SMART ANALYSIS OF MOST BUILD MULTISTORIED RCC BUILDING OF GULBARGA REGION
}

\author{
Tanveer Asif Zerdi ${ }^{1}$, Ghyan Sham Prasad Singh Khare ${ }^{2}$ \\ ${ }^{1}$ Research Scholar, Civil Engineering, JJT University, Rajisthan, India \\ ${ }^{2}$ Principal, Civil Engineering, Govt Engg college jagdalpur, Chhattisgarhi, India
}

\begin{abstract}
As a part work of searching the easy and simple way of structural analysis and design to the practical life line structure (Commonly permitted and constructed Reinforced cement concrete (RCC) Multistoried building structure in Gulbarga Region of Karnataka state), this work is carried out which is a breakthrough as it gives easy guide for analysis to many technocrats who are unconfident in practical structural design of day to day encountered structure. Extensive information of RCC multistoried building structures which are permitted hence got constructed in Hyderabad Karnataka is gathered, which is found as Ground plus three storied RCC Commercial building having regular frame layout. The different methods of structural analysis available in civil engineering and structural engineering domain are gathered by which the structure under consideration can be analyzed. From these different methods and procedures after careful study a simple method is picked so that it should be relatively easy and should not consume huge time. To be easily understood by unconfident technocrat of this region. Since the structure under consideration was having rigid jointed plane frame, and the degree of accuracy required in analysis for such a building is not very high, the Substitute frame method has been zeroed and used. The method is suitable even for hand computations for non sway structures.
\end{abstract}

Keywords: Concrete, RCC, Structural analysis, structural design, Practical life line structure

\section{INTRODUCTION}

Finding out of feasible easiest analysis way which can be adopted to do structural analysis and hence for structural design of practical life line structure this work is carried out. Author means the practical life line structure as a building structure which is frequently permitted and commonly constructed RCC multistoried building structure in Hyderabad Karnataka area ( Gulbarga, Bidar, Raichur, Yadgir Districts are considered over here) of Karnataka state. The first most frequently/commonly constructed structure is known by the author as life line structure. The topic Smart Analysis of most build Multistoried RCC building of Gulbarga Region is the part work of the research topic of the author namely "feasible analysis and design way for practical life line structure" is the outcome of persistent demand from many of the students, practicing engineers, some building designers, fresh engineering graduates and post graduates, specifically many practicing government engineers who are unable to design with confidence the building structure which they encounter normally in day to day life in spite of getting sufficient academic qualification, and frequently they are found visiting structural consultants for the same in this area that is ground plus three storied commercial building ., to arrive at a simplified and easy way of structural analysis and equally simplified and easy way of structural design method which can be searched and hence can be adopted (with confidence and without confusion and without tiresome and time consuming calculations) to the, frequently constructed RCC multistoried building structure amongst the tall structures permitted/constructed in Hyderabad Karnataka area of Karnataka state. By extensive nature of search and survey of books and journals we can get many methods of structural analysis and design philosophies available in civil engineering domain. Different analysis methods and different structural design philosophies by which the above arrived frequently constructed RCC multistoried building structure of Hyderabad Karnataka area can be analyzed, and also as a step towards to arrive at the easiest and simplest analysis method to carry out structural analysis of the structure under consideration can be done (With confidence, without confusion and without tiresome and time consuming calculations and without using large memories of the computers and advanced structural analysis software's which are available in the market, without much affecting the limitations of technicalities like economy elegance, durability and safety and serviceability conditions by adopting assumptions/idealizations. This analysis/design is done through extensive survey of different books of civil and structural engineering domain, and journals, different Indian standard codes of practice etc. Calculation of exact bending moments in single span slabs or beams do not pose any problem. They can be obtained directly using co-efficient for standard loading cases available in various Indian standard design aids. co-efficient for continuous beams/slabs with approximately equal spans (Variation between long and short span not exceeding $15 \%$ of long span) and carrying uniformly distributed load. The co-efficient for equal spans continuous 
slab/beam for other standard loading like central point load or equal point loads at $1 / 4^{\text {th }}$ or $1 / 3^{\text {rd }}$ span points are also available in various design aids.[1] The dual structural system consisting of special moment resisting frame (SMRF) and concrete shear wall has better seismic performance due to improved lateral stiffness and lateral strength. [2]. The configurations of RC moment resisting framed building structure with different arrangements of shear walls are considered for evaluation of seismic performance, so as to arrive at the suitable arrangement of shear wall in the structural framing system for better seismic resistance [3] Elaborate mathematical/physical models can only be built once a structural system has been created. Such models are needed to evaluate seismic performance of an existing system and to modify component behavior characteristics (strength, stiffness, deformation capacity) to better suit the specified performance criteria [4]. "the performance is determined by comparing the "pushover" capacity curve of the building with Bangkok's seismic demand spectra. The demand spectra are derived from the constant-ductility yield strength demand spectra of predicted earthquake ground motions in Bangkok for various return periods. A 9-story frame building in Bangkok is chosen as a case study to demonstrate the capability of the procedure. A research plan to apply this procedure to check the seismic performance of many existing buildings in Bangkok is also presented [5] .In this study, a typical mid-rise residential building and a typical low-rise commercial building in Bangkok are selected and examined in details. However, only the first case is presented in this report. The selected building is a 4 -story apartment. [6]

\subsection{Objective}

Pick the most permitted and build RCC multistoried building structures in Hyderabad Karnataka. The different methods of structural analysis available in civil engineering and structural engineering domain are to be gathered by which the structure under consideration can be analyzed. From these different methods and procedures after careful study a simple method is to be selected which should be relatively easy and should not consume huge time, to be easily understood by unconfident technocrat of this region who are unable to do the structural analysis of day to day encountered RCC multistoried building structure.

\section{METHODS AND METHODOLOGY}

The different methods of structural analysis available in civil engineering and structural engineering domain are gathered by which the structure under consideration (Ground plus three storied commercial building which is the most constructed tall building of Gulbarga region which is known as Hyderabad Karnataka area) can be analyzed. From these different methods and procedures after careful study a simple method is picked so that it should be relativelyeasy and should not consume huge time. To be easily understood by unconfident technocrat of this region. The method to be suitable even for hand computations for non sway structures also.

The different approaches to structural analysis are given below Elastic Analysis based on Elastic Theory.

Limit Analysis based on Plastic Theory or Ultimate Load Theory.

\section{RESULTS AND DISCUSSION}

The different methods of structural analysis available in civil engineering and structural engineering domain are gathered by which the structure under consideration (Ground plus three storied commercial building which is the most constructed tall building of Gulbarga region which is known as Hyderabad Karnataka area) can be analyzed. From these different methods and procedures after careful study a simple method is picked so that it should be relatively easy and should not consume huge time. To be easily understood by unconfident technocrat of this region. The method to be suitable even for hand computations for non sway structures also.

The different approaches to structural analysis are given below

1) Elastic Analysis based on Elastic Theory.

2) Limit Analysis based on Plastic Theory or Ultimate Load Theory.

Normally, the elastic analysis is used in Working Stress (or permissible stress) Method of design (WSM), and the Limit analysis is used in Ultimate Load or Ultimate strength Method of design (ULM). The modified version of ultimate load method is called Limit State Method.

Thus, the Limit State Method of design includes design for ultimate limit state at which ultimate load theory applies, and also for service state at which elastic theory applies, thus requiring study of both the theories. At the same time, one should not get confused between the limit state philosophies of design and limit analysis. The latter is a method of analyzing a structure at collapse, while the former is a method of design for different limit states.

\subsection{Elastic Analysis}

Elastic analysis deals with the study of strength and behavior of the members and structures at working loads.

It is based on the following assumptions

i. Relation between force an displacement is

linear.(i:e Hooks law is applicable)

ii. Displacements are extremely small compared to the geometry of the structure in the sense that theyt do not affect the analysis.

Methods of elastic analysis can be broadly classified as under i. Classical Methods:

a) Method of Consistent Deformation, b) Slopedeflection Method c) Strain Energy Methods. 
ii. Relaxation/Iterative Methods:

a) Moment Distribution Method, b) Kanis Method.

iii. Computer Methods:

a) Matrix Methods b) Finite Element Method, c) Finite Difference Method.

iv. Approximate Methods:

a) Substitute Frame Method, b) Cantilever Method c) Portal Method.

v. Coefficient Method:

Coefficients given in design hand books or Codes are used to obtain bending moment, shear force etc.

With the availability and easy access to computers, the above methods will now be divided into two major groups. First group includes those methods which are more suitable for hand calculations for small works.

Method of Consistent Deformations, Moment Distribution Method, Kanis Method, Approximate Methods, and Coefficient Method come under this group. Substitute Frame Methods are suitable for analyzing the effects of horizontal loads on frames.

The second group is of the methods requiring the use of computers. Matrix Methods and Computer Methods described in parts 9 iii) and (iv) above come under this group.

Since the scope of this paper under consideration is to find a simple or easiest method of analysis amongst the different methods mentioned above for the Ground plus three storied commercial building, the discussion is limited to use of substitute frame method for analysis of building frames for vertical loading. The coefficient method or the approach of determining the design forces (e.g. bending m9oment, shear force, axial loads etc.) by use of coefficients available for standard loading cases, is very common in building design for analyzing simple frames and standard beams such as cantilever, simply supported, and continuous beams and slabs, and single bay single storied rectangular portal frames.

\subsection{Limit Analysis}

It is an analysis dealing with the study of strength and behavior of members and structure at collapse. It is based on plastic theory for structures made up of perfectly plastic material like steel, while it is based on ultimate load theory for structures of reinforced concrete, the behavior of which is characterized by crushing of concrete and yielding of steel at collapse. It must be borne in mind that this ultimate state is never allowed to be reached by the use of appropriate safety factors. However, the knowledge of strength and behavior at collapse is absolutely necessary to know the exact margin of safety.
The different methods of elastic analysis which are available as under

i. Classical Methods:

a) Method of Consistent Deformation, b) Slopedeflection Method c) Strain Energy Methods.

ii. Relaxation/Iterative Methods:

a) Moment Distribution Method, b) Kanis Method.

iii. Computer Methods:

a) Matrix Methods b) Finite Element Method, c) Finite Difference Method.

iv. Approximate Methods:

a) Substitute Frame Method, b) Cantilever Method c) Portal Method.

v. Coefficient Method:

Coefficients given in design hand books or Codes are used to obtain bending moment, shear force etc.

Amongst all these methods the substitute frame method is suitable as other methods are either time consuming in calculations or required computer for computations, for the analysis of ground plus three storied commercial building which is under consideration.. In the case of a multistoried structure, with the increase in height, the effect of horizontal loads requires consideration. Therefore, such structures are provided with rigid frames having rigid joints. If a multistoried structure is assumed to have simple connections, it is likely to collapse under the action of horizontal loads (in the absence of walls) due to lack of rigid connections between the component members. In a rigid frame, forces get distributed between the component members due to rigidity of connection and hence, analysis o the structures as a whole become necessary. Therefore, a four storied office building having a regular layout and which can be divided into a number of similar vertical plane frames has been considered in this discussion as this is the most constructed multistoried building structure of Gulbarga region. Since the degree of accuracy required in analysis for such a R.C .building is not very high, the substitute frame method has been found suitable amongst all the methods of structural analysis which are searched. The method is suitable for hand computation for non sway structures. In this method three different types of substitute frame ( viz Floor frame, Bay frame, Beam-column systems) can be used in the analysis.

\section{CONCLUSIONS}

Since the degree of accuracy required in analysis for such a R.C .building is not very high, the substitute frame method has been found suitable to the problem, simplest and easiest amongst all the methods of structural analysis which are searched. The method is suitable for hand computation for non sway structures. In this method three different types of substitute frame ( viz Floor frame, Bay frame, Beam-column systems) can be used in the analysis. Other methods are either time consuming in calculations or required computer for computations. 


\section{REFERENCES}

[1] Indian standard code of practice IS 456-2000.

[2] Akis tolga January (2004) "lateral load analysis of shear wall-frame structures".

[3] P. P. Chandurkar Dr. P. S. Pajgade May - June 2013 "seismic analysis of RCC frame building with and without shear wall" Vol. 3, Issue. 3,pp-1805-1810

[4] Can Balkaya and Erol Kalkan, Department of Civil Engineering; Structures Division; Middle East Technical University; Ankara 06531; Turkey 2003 Estimation of fundamental periods of shear-wall dominant building structures".

[5] Björk Hauksdóttir in February 2007. "Analysis of a Reinforced Concrete Shear Wall"

[6] Chung-Yue Wang and Shaing-Yung Ho (Nov 2007), in $2^{\text {nd }}$ nternational conference on urban disaster reduction nov-2007.

[7] "Pushover Analysis for Structure Containing RC Walls" 